\title{
Observando a Sala de Informática: O Licenciado em Informática e Novas Perspectivas com o Scratch como Objeto de Aprendizagem
}

\author{
Augusto C. O. De Almeida, Pablo C. Spinelli, Radamila O. Do Nascimento, Janiele \\ S. Costa, Danylla de M. Souza, Amanda O. A. Gomes, Anna R. da S. Marinho, \\ Jéssica da S. Souza \\ Instituto Federal de Educação, Ciência e Tecnologia do Rio Grande do Norte (IFRN) - \\ Natal - RN - Brasil \\ \{augusto_touya, janieletc, danylla_medeiros, kissohana\}@hotmail.com, \\ pablo.spinellìifrn.edu.br, \\ \{souza.jessicads, rada.maiden, raquelmarinho.linfor\}@gmail.com,
}

\begin{abstract}
This article describes a Scratch workshop held with the aim of reducing the teachers' estrangement and technologies. This difficulty was verified by the authors when they perceived how little or badly was the use of information technology in the teaching process. We discuss the pedagogical possibilities of this tool and of the informatics classroom as means for more meaningful teaching, in addition to discussing the teacher's role in the informatics classroom.
\end{abstract}

Resumo. O presente artigo descreve uma oficina de Scratch realizada com o objetivo de diminuir o estranhamento entre os professores e as tecnologias. Tal dificuldade foi constatado pelos autores ao perceber o pouco ou mau uso da informática no ensino. Dialoga-se sobre as possibilidades pedagógicas desta ferramenta e da sala de informática para um ensino mais significativo, além de discutir sobre a atuação do professor na sala de informática.

\section{Introdução}

A difusão das TIC (tecnologias da informação e da comunicação), com destaque para o computador e a internet, provoca mudanças econômicas, sociais e culturais. De acordo com Silva (2010), as tecnologias modificam também as estruturas cognitivas. Desse modo, compreende-se que a escola e seus sujeitos devem ter contato com estas novas tecnologias, especialmente a Informática, para promover sua inclusão digital. Para Diniz, Araújo e Brandão (2013), o computador pode ser usado para instrução técnica dos alunos, onde a informática seria uma disciplina isolada, ou uma forma inovadora de ensinar através das diversas habilidades que ela pode oferecer a partir do envolvimento com outras disciplinas.

Um dos projetos que tem promovido a inclusão digital e contribuído para a modernização da escola é o Programa Nacional de Informática na Educação (PROINFO). Criado em 1997, desde então este projeto tem sido implantado em escolas públicas de ensino básico, equipando-as com computadores e acesso à internet. Os objetivos delimitados pelas diretrizes do PROINFO trazem a percepção de que o uso das tecnologias na educação pública seria capaz de diminuir as desigualdades sociais ao oportunizar igualdade no acesso a equipamentos e no gerenciamento de informações.

Embora o PROINFO traga como uma de suas diretrizes a formação e a atualização dos professores com relação às TICs, a realidade observada nas escolas 
públicas ainda mostra salas de Informática subutilizadas e sucateadas, principalmente devido à falta de profissionais capacitados para atuar neste ambiente. Tal falta pode ser suprida pelo licenciado em Informática, que pode ministrar aulas dessa área específica de conhecimento, promovendo a formação continuada dos demais docentes e mediando aulas de outras disciplinas com as TICs.

O licenciado em Informática pode utilizar metodologias adequadas para ferramentas computacionais. $\mathrm{Na}$ escola, este profissional seria o responsável por explorar as diversas alternativas de ensino apresentadas pela Informática, fazendo com que a comunidade escolar tivesse percepção de que esta área de conhecimento possui muitas vertentes, por exemplo, a produção de mídias e o uso de softwares educacionais e educativos, dentre outras.

A partir destas constatações, o presente artigo analisa uma oficina intitulada "Scratch para professores: Desenvolvimento e novas perspectivas para a sala de informática", ministrada no III Seminário de Docência e Contemporaneidade: Espaços de formação como campos de luta e de resistência, promovido pelo Instituto Federal de Educação, Ciência e Tecnologia do Rio Grande do Norte, campus Canguaretama.

Este trabalho apresenta as discussões levantadas pelos ministrantes e compartilhadas pelos participantes da oficina com relação à presença do PROINFO nas escolas públicas e à realidade da sala de Informática observada por eles. Após esta troca de vivências, ocorreu a introdução do software Scratch na perspectiva de ferramenta pedagógica capaz de auxiliar o trabalho docente, o que culminou na criação de um jogo virtual.

$\mathrm{Na}$ segunda seção, expõem-se as diretrizes do PROINFO, comparando-as à realidade corrente. Na terceira, discutem-se os desafios e as possibilidades da sala de Informática como ferramenta pedagógica. Na quarta, é analisado o potencial pedagógico do software Scratch. Na quinta, descreve-se a oficina que motivou a escrita desse artigo. Na sexta e última seção, apresentam-se as considerações sobre a atuação e propostas de trabalhos futuros.

\section{Problematizando o PROINFO: desde sua idealização às condições estruturais da realidade atual}

A escola começou a assumir identidade facilitadora da inclusão digital ao final da década de 1990, por meio de projetos como, principalmente, o PROINFO do Ministério da Educação (MEC). Como citado por Carvalho [2012, p. 16], "O programa nacional de informática na educação tem por objetivo a melhoria da qualidade do ensino aprendizagem, propiciando uma educação voltada para o desenvolvimento científico e tecnológico".

O PROINFO [Brasil/MEC 1997, p. 2] chegou com propostas inovadoras para a escola numa época em que "[...] a informática e as telecomunicações vêm transformando a vida humana ao possibilitar novas formas de pensar, trabalhar, viver e conviver no mundo atual, o que muito modificará as instituições educacionais e outras corporações".

Baseado, também, no preceito de que o acesso à informação é necessário para um Estado democrático e que uma sociedade não se desenvolverá sem possibilitar a inclusão dos seus cidadãos nos processos das novas tecnologias é, portanto, indispensável para a sociedade que a maioria de seus indivíduos saiba relacionar-se com elas. O PROINFO concebe o sistema educacional como "[...] o locus ideal para 
deflagrar um processo dessa natureza [...]" [Brasil/MEC 1997, p. 2], iniciado assim um movimento que trouxe estrutura para a criação de salas de informática nas escolas, objetivando uma melhor qualidade do ensino-aprendizagem, a criação de uma nova proposta de trabalho cognitivo que integrasse adequadamente as novas tecnologias da informação e metodologias de ensino para o conteúdo regular de maneira diferenciada pelas escolas.

Seu documento de Diretrizes [Brasil/MEC 1997] apresenta uma variedade de possibilidades para a sala de informática, tais como, até dois períodos de aula na sala por semana, cursos na área da informática para a comunidade. Além de prever um técnico de suporte em cada escola contemplada pelo programa e núcleos de tecnologia educacional responsáveis pelo apoio no processo de planejamento tecnológico das escolas, sensibilização e motivação das escolas para incorporação da tecnologia de informação e comunicação, capacitação dos professores e das equipes administrativas das escolas, além da realização de cursos especializados para as equipes de suporte técnico.

O documento de Diretrizes do PROINFO [Brasil/MEC 1997) advoga em favor de uma revolução na escola e no processo de ensino-aprendizagem. Contudo, mais de 20 anos após sua construção o que encontramos nas escolas públicas são salas de informática sucateadas, pouco usadas, sem profissionais com formação para assumir sua responsabilidade e professores que, muitas vezes, não estão envolvidos com as evoluções tecnológicas e não tem apoio pedagógico para planejamento e realização de atividades com o uso do computador. Dessa forma, um espaço que poderia ser melhor aproveitado como mediador de aprendizagem e criação de saberes e produtos de mídias, por vezes, se torna depósito da escola.

Para Teodoro (2015), mesmo com os diversos equipamentos tecnológicos na escola, professores se restringem ao quadro, giz e livro, pois tem medo das novas tecnologias. Kenski [2009, p. 134] confirma isto ao afirmar que, "Quando se fala no uso de recursos tecnológicos (desde um simples retroprojetor até o microcomputador) nas escolas, todos os professores se assustam. A maioria dos professores não sabe utilizálos, nunca aprendeu".

A falta de ações que promovam apoio pedagógico ao professor para a utilização da sala de informática e do computador como ferramenta de ensino-aprendizagem exclui o profissional docente e, consequentemente, o aluno de um espaço que ensina os envolvidos a subordinar as novas tecnologias em favor da humanidade, da vida social/cidadã e da educação. Teodoro (2015) reforça que o uso das novas tecnologias exige do professor uma observação de suas competências e habilidades e eu a tecnologia é um instrumento a favor da educação.

Assim, faz-se necessário ações que ajudem a fomentar o uso da sala de informática pelos professores e deem apoio, pois de acordo com Carvalho [2012, p. 15],

Apenas a presença da informática na educação não garantirá a qualidade no ensino, o aparato computacional, se não for bem entendido pode ser apenas mais uma estratégia fadada ao erro. Informatizar o ambiente escolar afeta muitos fatores, no que tange relação professor-aluno, processo ensino-aprendizagem, práticas pedagógicas, abertura para inovação, aulas diferenciadas, e formação do docente.

Nesse contexto, entra em "cena" a figura do profissional licenciado em 
informática, que recebe em sua formação fomentos e subsídios para uma atuação que pode variar do apoio no uso da sala de informática com outros professores, passando pelo ensino específico da informática à multi, pluri, inter e transdisciplinaridade.

\section{Da sala de informática: como atuar pedagogicamente e deixar o "laboratório"}

Costuma-se usar o termo "laboratório de Informática" para designar o ambiente equipado com computadores e/ou internet como ferramentas pedagógicas. Os autores do presente artigo, contudo, defendem ser um equívoco o uso deste termo.

Para começo de discussão, é preciso compreender o significado da palavra "laboratório". De acordo com o dicionário Houaiss [Laboratório 2004], laboratório é um "1. local com instalações e aparelhagem necessários para análises ou experiências (clínicas, industriais, químicas etc.) [...] 2. p.ext. lugar com equipamento próprio para pesquisas e experiências $<1$. de artes plásticas $><$ l. de línguas $>[\ldots]$ ”.

Ocorre nos laboratórios as experiências de testes e avaliação de alguma produção ou criação de produto. Em contraponto, nas salas de informática pode-se trabalhar com o conhecimento, de modo que a aprendizagem é o objetivo a ser alcançado e não um produto a ser analisado. Novamente para o dicionário Houaiss [Sala 2004], o termo "sala" nos leva à "[...] 2 local apropriado para o exercício de alguma função específica $<$ s. de reuniões $>[\ldots] 4$ B local onde são dadas aulas; classe 5 B grupo de alunos de certo ano acadêmico; turma [...]".

Com base nestas constatações, defende-se aqui o uso do termo "sala de informática" em substituição a "laboratório", pois os recursos desta sala são utilizados para a sistematização do conhecimento, levando à formação cidadã e crítica do aluno.

Quando os computadores começaram a serem inseridos na escola a partir de programas como o PROINFO, a princípio, os professores de outras áreas específicas seriam treinados para atuarem junto ao computador. Entretanto, a falta de proximidade nas demais áreas com a informática e a computação somada ao uso não sistematizado dos espaços e recursos tecnológicos trouxe um desestímulo a esses professores, desenvolvendo uma relutância quando o assunto é uma aula na sala de informática. Carvalho [2012, p. 22] parafraseia o MEC ao concordar que trabalhar dessa forma pode afastar os professores da sala de informática, pois nem todos têm o mesmo interesse em trabalhar com os recursos tecnológicos, também da exigência de pesquisa e criatividade em seu uso.

Para que as ferramentas da informática possam tornar-se efetivas na expansão do conhecimento e aprendizagem é necessário que o professor tenha conhecimento para discernir sobre suas ações e seu planejamento na sala de informática. Melhor dizendo, o professor deve ter seus objetivos bem definidos para esse tipo de atuação e ela não será efetiva se o aluno simplesmente reproduzir o conhecimento encontrado. Para tanto, é necessário que o aluno produza seu próprio conhecimento. Ao falar sobre as TIC's em sala de informática, Carvalho [2012, p. 22] afirma que

Se bem utilizadas em sala de aula, podem contribuir para o acesso a diferentes fontes de conhecimento, assim como pode ser um instrumento pedagógico que nos permite trabalhar com uma diversidade de programas e métodos, que podem facilitar a compreensão do conteúdo a ser trabalho durante as aulas.

Carvalho (2012) ainda complementa refletindo que essas tecnologias, quando 
submetidas a uma metodologia mais significativa, criam micromundos de aprendizagem que são capazes de fazer simulações, como reações químicas ou físicas, reprodução celular, de interação com o meio ambiente, de trabalho etc, que na realidade seriam rápidas ou muito lentas, perigosas ou que demandariam a compra de um equipamento de alto valor financeiro, sendo todas essas situações substituídas por um software simulador. Almeida et al [2016, s/p] enfatiza que

A inclusão desse recurso pode ser inútil se seu modo de uso não for adequado, não basta apenas disponibilizá-lo, os professores devem ser capacitados para promover a qualidade no ensino, através de amplas possibilidades, desenvolvendo práticas pedagógicas que não sejam apenas transmissões, repetições e memorizações de conteúdos.

Assim, quem dentre os profissionais da educação poderia ter a formação adequada para prover ações de apoio pedagógico e desenvolver atividades no núcleo específico da informática? O Projeto Pedagógico de Curso (PPC) da licenciatura em informática do Instituto Federal de Educação, Ciência e Tecnologia do Rio Grande do Norte [Brasil/IFRN 2012] apresenta o licenciado em informática como esse profissional que pode atuar nas áreas de desenvolvimento de atividades de docência e pesquisa em computação e educação, aplicação, avaliação e desenvolvimento de software educacional, planejamento e execução de currículos e programas de capacitação profissional que empreguem a Informática como suporte e apoio educativo, organização e administração de laboratórios de Informática.

Este licenciado em informática pode atuar em diferentes nichos da escola, além de oferecer suporte para outros professores durante as aulas na sala de informática. Os licenciados podem ministrar aulas específicas da área de acordo com suas possibilidades (software/hardware), desenvolver ações interdisciplinares e atuar na formação continuada de outros professores para o uso das ferramentas computacionais.

É importante ressaltar que aqui não é buscado tomar o licenciado em informática como o "Senhor da sala de informática", mas expô-lo como um profissional que tem fundamentos em sua formação para atuar com os recursos da sala de informática e com a escola, assim tendo diversas possibilidades de atuação. Pois, por vezes, as ações na sala se resumem apenas a atividades de pesquisa, como descreve Carvalho (2012), que reconhece a relevância dessa metodologia, mas admite que, quando falamos em internet na escola, automaticamente nos restringimos a fazer pesquisa e coleta de dados.

Retomando Almeida et al [2016, s/p], em seu trabalho sobre a as atividades na sala de informática em uma escola com uma licenciada em computação, reconhecem que

[...] a presença de um professor proativo, devidamente qualificado e capacitado para o desempenho destas funções é de extrema importância, pois o mesmo é capaz de orientar alunos e professores, suprindo a necessidade de ambos (embora fique sobrecarregado) onde as necessidades dos alunos de terem aulas de práticas tecnológicas e as dificuldades encontradas pelos professores por não terem habilidade e nem capacitação para desempenharem seu devido papel, também são supridas.

Assim, compreende-se que os licenciados em informática, além de ministrarem aulas do seu núcleo específico, direcionam sobre o uso correto e eficaz das ferramentas da informática, auxiliando na escolha de uma ferramenta mais adequada aos objetivos de uma determinada aula e atuando como orientadores para o uso dos recursos da sala 
de informática, que deixa de ser um laboratório e se transforma num lugar próprio para a construção e discussão de saberes e conhecimento, ou seja, uma sala de informática.

\section{Scratch como alternativa pedagógica no ensino básico}

Ao mencionar as diversas possibilidades de atuação do licenciado em informática, uma de grande potencial de aprendizagem é a apresentação de softwares que facilitem o ensino. Neste contexto, tem-se os objetos de aprendizagem (OA) que, segundo Carneiro e Silveira (2014), podem ser materiais analógicos ou digitais, contanto que possuam uma finalidade pedagógica de apoio ao aprendizado. No contexto da Informática, os OA podem ser descritos

[...] como quaisquer materiais eletrônicos (como imagens, vídeos, páginas web, animações ou simulações), desde que tragam informações destinadas à construção do conhecimento (conteúdo autocontido), explicitem seus objetivos pedagógicos e estejam estruturados de tal forma que possam ser reutilizados e recombinados com outros objetos de aprendizagem (padronização). [Carneiro, Silveira 2014, p. 239]

Para Teodoro [2015, s/p], "através do computador o docente pode utilizar recursos que permitem crescimento profissional. Utilizar software é uma metodologia que enriquece a aula do professor além de contribuir para formação crítica do aluno". Como exemplo de possível OA, tem-se o Scratch.

O Scratch é um ambiente de desenvolvimento de aplicações produzido pelo Lifelong Kindergarten no Instituto de Tecnologia de Massachusetts e disponível no sítio https://scratch.mit.edu/, de modo que o usuário pode criar uma conta e salvar seus projetos no repositório online. Existe ainda a possibilidade de trabalhar offline, instalando-se o Scratch no computador.

Um projeto no Scratch é formado por um palco e por diferentes objetos chamados "atores". Trabalha-se por meio de blocos que podem ser encaixados, os quais se referem às ações a serem realizadas por cada ator, que são executadas em um palco, ou seja, em um plano de fundo [Aureliano, Tedesco 2013].

Para utilizar este software não é necessário dominar uma linguagem de programação, pois o Scratch trabalha com blocos que se encaixam para montar o código. A viabilidade de utilizar os blocos em diferentes combinações permite a criação de OA, tais como jogos e animações. Portanto, embora o Scratch tenha sido concebido para uso do público jovem (dos 8 aos 16 anos), ele também é utilizado por adultos na construção de projetos pedagógicos que envolvem mais de uma disciplina. [Ribeiro 2014]

Neste contexto, o Scratch corresponde à descrição de OA proposta por Aguiar e Flôres [2014, p. 12], sendo que,

Os OAs podem ser criados em qualquer mídia ou formato, podendo ser simples como uma animação ou uma apresentação de slides, ou complexos como uma simulação. Normalmente, eles são criados em módulos que podem ser reusados em diferentes contextos.

O ambiente virtual apresenta um potencial significativo para o uso de OA, pois nele o usuário pode testar diferentes hipóteses e estratégias, obtendo no fim um feedback [Aguiar, Flores 2014]. Tais características são observadas no Scratch, onde a 
aplicação pode ser executada e analisada no mesmo ambiente.

Diversos autores [Silva et al 2014], [Sobreira, Viveiro, D'Abreu 2016], [Batista et al 2016], [Oliveira, Rodrigues, Queiroga 2016] exemplificam em suas publicações o uso do Scratch como mediador no ensino de diferentes temáticas para alunos da educação tanto básica quanto superior, não se atendo somente à lógica de programação.

Embora o manuseio do Scratch seja simples e sua linguagem interativa, o usuário precisa ter em mente quais os objetivos deseja alcançar, qual o problema a ser resolvido. Observa-se, assim, que este software é capaz de desenvolver a motivação e a criatividade por meio da resolução de situações-problema. [Silva, Morais, Batista 2014]

As aulas com o Scratch possibilitam a aprendizagem baseada no conceito de design, o qual

[...] enfatiza a concepção (criar e não apenas utilizar ou interagir), a personalização (criando algo que é pessoalmente significativo e relevante), a colaboração (trabalhando com outras pessoas nas criações) e a reflexão (revendo e repensando as práticas criativas de cada um). [Fraça et al 2014, p. 1504]

Com isso, o Scratch oferece duas vertentes de atuação ao docente: primeiro, como produtor de aplicativos específicos para trabalhar um conteúdo curricular; e segundo, como orientador para que o próprio discente desenvolva animações por meio do software. Ou seja, o Scratch se apresenta como um OA ou como meio para a construção de OA. Partindo dessas premissas, entende-se que o Scratch pode auxiliar no desenvolvimento de soluções inovadoras para problemas inesperados, promovendo uma aprendizagem criativa.

\section{A oficina e seus resultados}

A oficina, objeto deste relato de experiência, foi dividida em três partes bem definidas: Discussões sobre a sala de informática, de como foi inserida na escola pública até como preparar uma atuação com seu uso; Introdução ao Scratch; e o Desenvolvimento de aplicações. Como participantes, a oficina contou com licenciados e licenciandos das áreas de informática, química, física, artes e pedagogia, todos com vínculos na escola pública.

Quanto às discussões sobre a sala de informática, abriu-se debate para que os participantes expusessem suas impressões sobre o assunto e discutissem entre si. Nesse momento, os ministrantes apresentaram o documento de Diretrizes do PROINFO (1997) e tópicos presentes no documento para que os participantes comparassem com a realidade das escolas em que trabalham. Com isso, os participantes refletiram sobre a atuação do PROINFO em suas ações didático-pedagógicas e as da própria escola com o uso das salas de informática. Segundo os relatos dos participantes, este uso era esporádico e somente para atividades de pesquisa na internet, ou mesmo a transformação da sala em almoxarifado.

As atividades de pesquisa mencionadas geralmente se reduziam a buscar na internet respostas para questionários produzidos pelos docentes. Durantes as discussões percebeu-se que esses professores não tinham conhecimento de ferramentas computacionais que fugissem ao duo internet-pacote office e que isso afeta duramente a atuação dos professores com o uso do computador, visto que não há aproveitamento de outros recursos da Informática e perpetuando a concepção da pesquisa como a única metodologia passível de ser realizada na sala de Informática. 
Após a discussão e a fim de desmistificar a programação como uma atividade muito difícil e trabalhosa, os ministrantes orientaram os cursistas em uma dinâmica de encenação. Seguindo o modelo do Scratch, um dos participantes tomou o papel de uma bola e outros dois assumiram a função de paredes, de modo que, ao bater numa parede, a bola devia virar e continuar se movendo até a parede oposta. Um dos ministrantes ficou responsável por posicionar os atores e orientar os movimentos executados. Os participantes que restaram como plateia falaram os comandos para iniciar e para mover os atores.

Este momento foi bastante descontraído e auxiliou os participantes a compreender o funcionamento de algumas particularidades da programação, como a sequência de comandos, o loop (repetição) e a estrutura condicional, além de observar e corrigir seus próprios erros na construção do "código" que falaram. Estes erros se referiram a comandos incompletos, ocasionando comportamentos inesperados dos atores.

A introdução ao Scratch teve caráter expositivo dialogal e os participantes acompanharam visualmente por meio de um projetor, sempre com monitoramento de um dos ministrantes. O Scratch foi apresentado como uma opção de objeto de aprendizagem a ser usado na sala de informática. Buscou-se mostrar que, embora tenha sido criado como um software de introdução ao mundo da programação, suas funcionalidades permitem que o professor crie suas próprias aplicações com o conteúdo de sua disciplina ou que o aluno desenvolva algo com o assunto do dia, até mesmo uma avaliação dinâmica em que o aluno e professor consigam um feedback automático. Discutiu-se também sobre os desenvolvedores do software, o layout e toda a exibição dos blocos de comando.

O desenvolvimento contou com participação ativa dos cursistas. Embora as aplicações estivessem definidas, as animações foram construídas com a ajuda de todos, aberto para argumentações sobre quais blocos seriam usados.

Dentre os projetos reproduzidos, houve a "Bolinha de vai-e-vem", representando a dinâmica inicial, e um jogo apelidado de "Caça fantasmas" que foi mostrado como exemplo pelo fato de ter sido desenvolvido por alunos do $3^{\circ}$ ano do ensino fundamental de uma escola da qual os ministrantes tinham vínculo. Nesse "Caça fantasmas" uma bola deveria percorrer um pequeno labirinto até pegar um fantasma que ficava mudando de posição na tela (semelhante ao PacMan), esse pequeno jogo teve como objetivo mostrar uma aplicação dinâmica para os participantes. Nele, além dos personagens, existiu um sistema de pontuação com penalidades caso a bola toque nas paredes do labirinto e os pontos mostrados na tela. Os participantes demonstraram interesse nessas animações e nas possibilidades que o Scratch poderia proporcionar, enxergando no software uma alternativa pedagógica produtiva, além de uma facilitadora de conteúdo, para os alunos e tem grandes possibilidades de usarem o software em suas aulas.

\section{Considerações finais}

Embora o PROINFO tenha sido de modo geral efetivo por equipar as escolas com computadores e acesso à internet, apenas estes equipamentos no ambiente escolar não modificou os processos de ensino e de aprendizado. Autores defendem, além da sala de informática equipada, a necessidade do trabalho colaborativo entre a comunidade escolar e da formação de recursos intelectuais para o manuseio adequado destes materiais.

O uso da sala de Informática como ferramenta pedagógica esbarra muitas vezes 
no despreparo e na desinformação dos professores nas escolas públicas. É necessário maior comprometimento com relação à formação docente para usar as tecnologias em sala aula e na escola de modo geral. Deve-se mostrar a estes a abrangência de conhecimentos contidos na Informática. A fim de mediar a comunicação entre os professores e as tecnologias, devem ocorrer esforços para que se concretize a presença de profissionais licenciados em Informática ou computação nas escolas públicas de Ensino Básico.

Os licenciados em informática podem ajudar a dar sentido ao uso da sala de informática nas escolas por meio de ações pedagógicas para apoiar professores que queiram usar das ferramentas da informática em suas aulas. Em paralelo, esse profissional pode aprofundar os conhecimentos de alunos e professores sobre a informática.

No presente artigo defende-se a substituição do termo "laboratório" por "sala de Informática", de modo que este local se torne efetivamente um ambiente de construção coletiva de saberes.

O software Scratch oferece um ambiente interativo para a programação de aplicações, permitindo que mesmo indivíduos sem conhecimento sobre linguagem de programação possam construir animações por meio dos blocos de encaixe. Os participantes da oficina se mostraram interessados e positivos acerca deste software como ferramenta em sua prática. Percebe-se que, com o apoio de um licenciado em Informática e recebendo uma constante atualização em relação às possibilidades de uso das tecnologias na escola, os professores de disciplinas específicas serão capazes de vencer o receio do computador e integrá-los à sua prática pedagógica, contribuindo para a modernização e a inclusão digital da comunidade escolar.

\section{Referencias}

Aguiar, E. V. B. e Flôres, M. L. P. (2014) "Objetos de aprendizagem: conceitos básicos”, p. 12-28, in: Tarouco, Liane M. R. et al (Orgs.) Objetos de aprendizagem: teoria e prática. 1. ed. Porto Alegre: Evangraf, 2014.

Almeida, J. S., Araújo, M. S., Lima, S. M. S., Sousa, K. C. e Felix, O. M. S. (2016) "O laboratório de informática como ambiente articulador de saberes na prática pedagógica de professores", in: Congresso Nacional de Educação (III CONEDU). http://www.editorarealize.com.br/editora/anais/conedu/2016/TRABALHO_EV056 MD1 SA4 ID4152 04082016215911.pdf. Julho de 2020.

Batista, E. J. S., Castro Jr, A. A., Canteiro, S. V., Bogarim, C. A. C. e Larrea, A. A. (2016) "Uso do Scratch no ensino de programação em Ponta Porã: das séries inicias ao ensino superior", in: V CBIE. XXII WIE. Anais do WIE. https://www.brie.org/pub/index.php/wie/article/view/6863/4741. Julho de 2020.

Brasil, Instituto Federal de Educação, Ciência e Tecnologia do Rio Grande do Norte (2012) "Projeto Pedagógico do Curso Superior de Licenciatura em Informática na modalidade

presencial". file:///C:/Users/Oliveira/AppData/Local/Temp/Licenciatura\%20em\%20Informatica\% 202018.pdf. Julho de 2020.

Brasil, Ministério da Educação e do Desporto (1997) "Programa Nacional de Informática na Educação - PROINFO: Diretrizes". https://goo.gl/rP6iNj. Julho de 2020. 
Carneiro, M. S. F. e Silveira, M. S. (2014) "Objetos de Aprendizagem como elementos facilitadores na Educação a Distância", Educar em Revista, Curitiba, Brasil, Edição Especial n. 4/2014, p. 235-260. Editora UFPR.

Carvalho, J. M. (2012) "O uso pedagógico dos laboratórios de informática nas escolas de Ensino Médio de Londrina", Trabalho de Conclusão de Curso (Graduação em Pedagogia) - Universidade Estadual de Londrina, Londrina.

Diniz, J., Araújo, S. S. e Brandão, X. (2013) "Uma análise do perfil profissional do licenciado em Informática”, p. 2202-2211, in: IX CONGIC. 2013. Anais.

França, R. S., Ferreira, V. A. S., Almeida, L. C. F. e Amaral, H. J. C. (2014) "A disseminação do pensamento computacional na educação básica: lições aprendidas com experiências de licenciandos em computação", p. 1473-1482, in: XXII Workshop sobre Educação em Computação (WEI).

Kenski, V. M. (2009) "Didática: o ensino e suas relações, São Paulo, 14ed, Papirus.

Laboratório (2004) in: Houaiss, A., Minidicionário Houaiss da língua portuguesa, Rio de Janeiro, Objetiva.

Moreira, K. C., Bulcão, J. S. B. e Souza, D. M. (2015) "Programando Animações Educacionais Utilizando Uma Linguagem De Blocos Para Estudantes Do Ensino Fundamental", p. 73-73, in: COIPESU, João Pessoa. Anais de resumo - COIPESU. João Pessoa.

Oliveira, M. V., Rodrigues, L. V. e Queiroga, A. P. G. (2016) "Material didático lúdico: uso da ferramenta Scratch para auxílio no aprendizado de lógica da programação", Anais do WIE. https://goo.gl/1D9aKk. Julho de 2020.

Sala (2004) in: Houaiss, A., Minidicionário Houaiss da língua portuguesa. Rio de Janeiro, Objetiva.

Silva, A. M., Moraes, D. A. S. S. e Batista, S. C. F. (2014) "Educação Ambiental: Scratch Como Ferramenta Pedagógica No Ensino De Saneamento Básico". Renote. UFRGS. https://goo.gl/UbPXGR. Julho de 2020.

Silva, E. G., Barbosa, A. F., Neto, S. R. S., Lopes, R. H. O. e Rodrigues, A. N. (2014) "Análise de ferramentas para o ensino de Computação na Educação Básica", p. 1495-1504, in: XXXIV CSBC. Brasília.

Silva, M. A. R. (2010) "O uso pedagógico das TIC como expansão das capacidades: o ProInfo Natal/RN”, UFRN, Dissertação. https://goo.gl/9vwjYm. Julho de 2020.

Sobreira, E. S. R., Viveiro, A. A. e D'Abreu, J. V. V. (2016) "Do Paper Circuit à programação de Arduino com Scratch: uma sequência didática para aprendizagem do conteúdo de energia nos anos iniciais do ensino fundamental", p. 456-465, in: V CBIE. XXII WIE. Anais do WIE.

Teodoro, R. A. P. (2015) "Perspectivas sobre a utilização da informática na prática docente: O computador como recurso tecnológico nas aulas de matemática", Revista Saberes, Ed. 005. https://tinyurl.com/y9vyk8qy. Julho de 2020. 